book review

\title{
How to do Things with Green Culture
}

\section{ANGI BUETTNER}

VICTORIA UNIVERSITY OF WELLINGTON

Adrian Parr

Hijacking Sustainability

MIT Press, Cambridge, MA, 2009

ISBN 9780262517461

RRP $£ 9.95$

Richard Maxwell and Toby Miller

Greening the Media

Oxford University Press, Oxford, 2012

ISBN 9780195325201

RRP \$24.95

Environmentalism, sustainability, ecology, climate change, a green new deal: these words and phrases have become so prominent in popular discourse that to many they demonstrate the rise of an environmental sensibility, a shift in human understanding of nature and our place in it and an acknowledgement that, in the face of environmental degradation and climate change, we need to mend our ways to ensure a future for the planet. More and more people care about ecology, the way 
all our human systems-economics, energy, the way we run our lives-are interdependent parts of the natural world. Back in 1949, Aldo Leopold called for an 'ecological conscience' in A Sand County Almanac, the book that brought the need for environmental stewardship into public discourse and popular culture. ${ }^{1}$ This call has been echoed by the doyens of the contemporary environmental movement, such as Rachel Carson, Paul Ehrlich, Edward Wilson and Bill McKibben. In the face of ongoing environmental degradation, however, many see the current enthusiasm for all things green not as reflecting a new-found environmental sensibility but as ecochic, the result of the integration of environmental concerns into the logic of late capitalism. Rather than signalling the beginning of a new environmental consciousness, the phenomenon of eco-chic foreshadows the end of the environmental movement in the age of the anthropocene.

Two recent books are concerned with how our technologies and cultural practices affect the environment. Adrian Parr's Hijacking Sustainability deals with the fallout of sustainability having gone mainstream. Richard Maxwell and Toby Miller's Greening the Media negotiates the environmental impact of media corporations and ubiquitous media consumption.

In Hijacking Sustainability, Adrian Parr provides a snapshot of sustainability culture in the United States today. Put simply, sustainability culture is all things to do with sustainable development and sustainable practices across various cultural fields. The book delivers what its title promises: its core argument is that the more popular sustainable development becomes, the more commodified it gets. Corporate, governmental and military interests hijack sustainability to further their own capitalistic interests, and thus endanger the environmental sustainability movement's capacity to influence climate change and poverty.

Parr begins by making the case that sustainability has gone mainstream. The corporate sector's eco-branding and Hollywood eco-chic (Prius-driving environmental activist stars and the like) are two of the strongest examples of mainstreaming. The first half of the book offers case studies that trace how the 'enthusiasm for all things green' (10) has taken hold. Along with showing the popularisation of sustainability culture, these chapters disentangle the motivations and politics of hijacking sustainability. The chapter on big business questions the difference between eco-branding and genuine sustainable goals of multinational 
corporations. The problem lies with how capitalist consumption and sustainable living are able to go hand in hand. The chapter on the 'greening' of Hollywood is an extension of the discussion of the corporate sector that questions the politics championed by the likes of Leonardo di Caprio and the effectiveness of popular culture. Again, as with eco-branding, Parr pushes the difference between fashionable green content and the actual environmental politics of the industry. She asks to what extent Hollywood celebrity as a product of commodity culture can advance social and environmental justice. According to Parr there is a tension between the logic of late capitalism and the logic of sustainability culture: the logic of consumption versus the logic of thrift. Parr questions whether Hollywood activism can be more than mere fashion and actually produce a cultural discourse different to the dominant one of commodification.

The next field Parr covers is the appropriation of the discourse of community, a core site for the expression of a sustainable, green and just life in the environmental and sustainability movement of the 1970s. In Parr's analysis, the counter-culture and hippie commune has been hijacked by real estate developers and turned into the gated community. Under the smokescreen of the eco-village, social life is fetishised and commodified within an exclusionary politics. The following two chapters discuss how the greening and then de-greening of the White House under the Carter and Reagan administrations has been entangled with the legitimation of federal power and the increased militarisation of the United States in the cause of national security.

After demonstrating the popularisation of sustainability culture and the incongruities of sustainability going mainstream, Parr shifts to actual practices within sustainable development. The second half of the book focuses on the areas that pose the main challenges to sustainability, such as waste, disaster relief, slums and poverty. Consequently, the critical emphasis shifts from cultural criticism and discourse analysis to the design disciplines (architecture, design, planning) and their practical focus on green design. The chapters in this part of the book deal with the implications of the popularisation of sustainability, or what Parr calls 'converting to the green cause', (1) in all fields of cultural production. Parr works towards understanding the politics of sustainability culture as a 'cultural hegemonic', (15) that is, as a system of knowledge that manages an environmental sensitivity. Thus 
understood, sustainability culture is the cultural shift to social and environmental activism in the face of social injustices and environmental degradation. As such, sustainability culture has an affective and ethical force. There is therefore a need to examine how and to what end sustainability culture and its cultural objects are used. Are they incorporated into the logic of late capitalism or do they serve as an engine of social change? The political function of sustainability culture is caught up in the politics of representation and mediation, and the power relations produced by the discourses of this representation. At the same time, the ways in which culture engages the problems of environmental exploitation and social injustice brings into being subjectivities, and thus activates a sense of agency for the disenfranchised.

Richard Maxwell and Toby Miller's Greening the Media also deals with power imbalances produced by cultural practices, this time practices surrounding media technologies. It is a fascinating book about 'the myriad ways that media technology consumes, despoils, and wastes natural resources', (1) and all the more important since the facts provided and the questions posed are not what you normally find in academic, professional or popular accounts of media technologies and what we do with them. The book balances the performance of two analytical tasks: an analysis of the ecological impacts of media technology, and an analysis of media studies and related disciplines that have previously addressed (or not) the environmental impact of media technology. The authors call for a new cultural history of the media that provides a material history of media technology and takes the physical environment into account beyond the political and economic contexts addressed in conventional media history. Such a materialist ecology approach to media necessarily challenges the way media studies has functioned so far. Maxwell and Miller's book provides an eye-opening account of what is happening in our media environment and shows just how much new research needs to be done in media studies, such as work into media labour 'below the line of elite industry research'. (16) The book demonstrates how the many areas and issues that need to be investigated cannot be examined in an adequate manner by the traditional single scholar and monograph model. They call for a new model of knowledge production involving collaborative research teams comprised of scholars and activists from across the disciplines. 
A strong sense of an ecological ethics pervades the whole book and the range of work this does shows in a key paragraph:

The prevailing myth is that the printing press, telegraph, phonograph, photograph, cinema, telephone, wireless radio, television, and internet changed the world without changing the Earth. In reality, each technology has emerged by despoiling ecosystems and exposing workers to harmful environments, a truth obscured by both symbolic power and the power of moguls to set the terms by which such technologies are designed and deployed. Those who benefit from ideas of growth, progress, and convergence, who profit from high-tech innovation, monopoly, and state collusion-the military-industrial-entertainment-academic complex and the multinational commanders of labor-have for too long ripped off the Earth and workers. The implications are stark. (9)

Because media technology is a large-scale contributor to our global ecological crisis, with a direct impact on climate change, pollution, biodiversity decline and habitat decimation, media scholars and educators must ask how much media technology is necessary. This is a challenging question in the face of consumerism as cultural norm within a system of capitalism driven by the logic of growth.

Both the ecological analysis of media technology and the redirection of media studies towards the possibility of a materialist ecology are skilfully interwoven throughout the book. The chapters are rich, factual case studies of the media's environmental and labour problems. Chapter 1 addresses media consumers and the material and ethical issues engaged by the rapidly growing production and consumption of new media technologies. Chapters 2 and 3 assess the material environmental impact of media technologies. Chapter 4 examines the relationship between the environment and the conditions of labour in the global media industries from assembly lines to salvage yards. Chapter 5 discusses green global governance and the design, deployment and regulation of new media industries.

There is real power in the book's presentation of carefully researched facts on the sheer scale of environmental destruction caused by media technology. Another strength of the book is that it does not end on a liturgy of destruction or a call for necessary limitations on consumption but moves towards the possibilities of green media governance, green citizenship, and green media design. The final two 
chapters and conclusion develop ways to uncover the environmental and labour conditions within global media industries and propose how to change them for the better. Throughout the book, the authors integrate into their analysis media consumers, activists, researchers and policy makers alongside the material, physical histories of media technologies and practices, thus opening up possibilities for change. Maxwell and Miller insist that the way to green the media is 'by greening media studies' (21) and Greening the Media provides a model of green media studies at work.

In line with the strong ecological sensitivity displayed in the book, Maxwell and Miller also call for activism and policy work alongside research into the information and communication technologies. In their account, future green media studies will:

elaborate a political vision that cultivates connectedness among consumers via green citizenship-a shared commitment to confront the eco-crisis and press for greener governance through media policy. (30)

This is a tall order and certainly beyond what media studies has conventionally seen as its responsibility. I want to end this review with a few observations on the idea of greening media and cultural studies, or any other discipline for that matter. Both Hijacking Sustainability and Greening the Media have a certain inherent level of advocacy. Maxwell and Miller want their book to help bring about sound environmental policy and regulation of media industries. Parry wants her cultural critique of sustainability culture to offer an alternative narrative of the collective good which can help bring about social and environmental justice for those disenfranchised by corporate, military, and government interests. If analysing environmental issues and concerns in a 'green way'-that is, by doing 'green cultural criticism' of 'green culture'-is about furthering green activism it nonetheless raises questions about disciplinary fields and interdisciplinarity or cross-disciplinary work as well as questions about theory and research method. Within academic discourse the environment and environmental studies have been seen as challenges to the humanities and to how we conceptualise their social function. By necessity, the study of the environment requires interdisciplinary work. Engaging with the environment beyond the level of the metaphorical reveals the need to reconceptualise our forms of knowledge production. Some have already asked whether the humanities disciplines are ready to engage with the environment. 
In the context of cultural studies Phaedra Pezzullo has pointed out some of the challenges that might arise if we identify, interpret and intervene within and on behalf of the environment. She argues that dealing with the environment exposes key limitations within the humanities, such as an emphasis on the logic of representation that reinforces a dualism between nature and culture. ${ }^{2}$

Engaging with the environment necessarily raises questions of advocacy, intervention and action. Any work engaging environmental issues is perceived as having a social agenda. This causes problems of authority within a university environment which remains largely determined by the view that advocacy is not analysis. But questions of advocacy and analysis, of ethics and scholarship, of theory and critical engagement, have always been at the core of any discipline that deals with culture and power relations. The study of the environment and the growing green culture that now surrounds it challenges how we gather information and produce knowledge. As both Hijacking Sustainability and Greening the Media show, it also offers us opportunities to rethink the relation between social responsibility and the kind of work we do.

Angi Buettner researches in media and environmental communication. She is currently working on a project titled 'Climate Change and Popular Culture'.

\footnotetext{
-NOTES

${ }^{1}$ Aldo Leopold, A Sand County Almanac and Sketches Here and There, Ballantine Books, New York, 1966.

2 Phaedra Pezzullo, 'Overture', Cultural Studies, vol. 22, no. 3-4, 2008. pp. 361-8.
} 